\title{
Health risk by radon in drinking and sanitary water: assessment and control techniques
}

\author{
Patania $^{1}$ F.,Lo Nigro ${ }^{2}$ S..,Nocera ${ }^{1}$ F. \\ ${ }^{I}$ Environmental Applied Physics \\ ${ }^{2}$ Physic Department \\ University of Catania, Italy
}

\section{Abstract}

This paper is to inform people about a recently known hazard for drinking and sanitary water, which is still not well investigated as it is only in the last six years that scientific people have been aware of the problem and began to face it seriously: water pollution by Radon $(\mathrm{Rn})$ radioactivity.

To this aim are shown dangerous health effects proved by scientific investigations carried out in many countries, the main theories an formula coming from both different theoretical and experimental research to measure $\mathrm{Rn}$ concentration in water. The last proposal, coming from both authoritative searches and organisation, to fix health safety concentration level. Finally, it is proposed to establish the first limit of $\mathrm{Rn}$ concentrations in water to assure human safety and some control techniques to reduce $\mathrm{Rn}$ concentration below the reference safety limit.

\section{Introduction}

Among sources of ionising radiation fifty-five percent of the total is caused by Radon (Rn) (fig 1) [1] and during the last twenty years it has been well advertised that exposure to Rn causes lung cancer that occurs as a result of the dose of alpha energy emitted by Rn decay products delivered to target cells in the lung [2].

The U.S. Environmental Protection Agency (EPA) estimates that the number of lung cancer deaths due to Radon residential exposure is approximately 13.600 [3] 


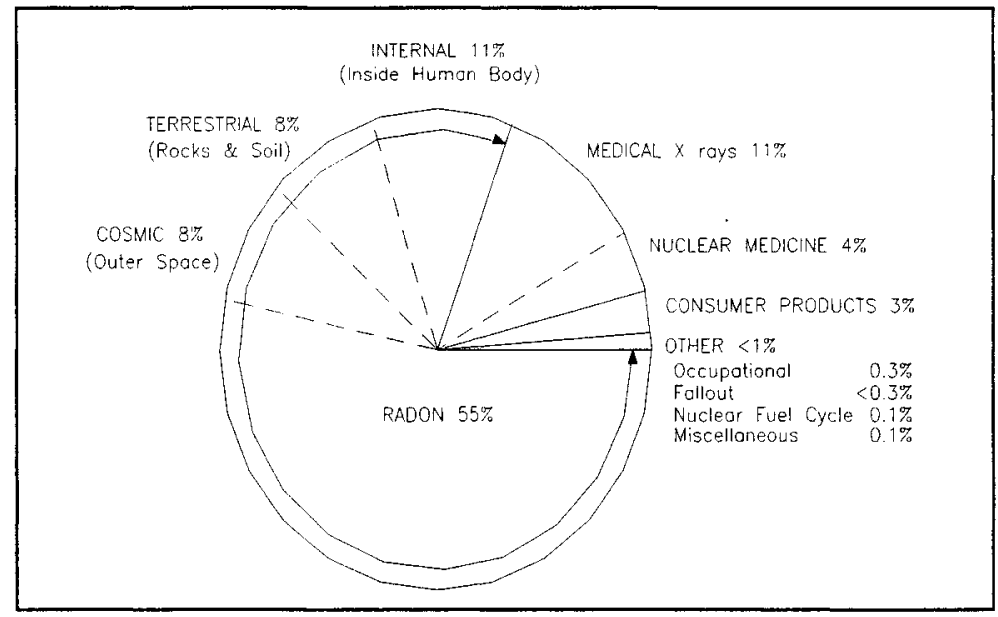

Figure 1: Sources of Radiation Exposure

Radon is the heaviest mono-atomic gas and there are three isotopes of atomic weight $219,220,222$. The gas is both colourless and odourless so it presents a sly behaviour for human health, in fact people discovers its presence only after have suffered heavy health damage [4].

${ }^{222} \mathrm{Rn}$, the isotope of main concern, is produced by radioactive decay of Radium which, in turn, is a radioactive product of uranium.

Sources of Rn include soil, water, outdoor air and buildings materials and since Radium is widely distributed in earth's crust it is found in mineral that come in contact with underground water. In this way $\mathrm{Rn}$, which is soluble in water, is found in ground water too and in some cases significant concentrations have been observed [5]

The concentration appears to depend upon the structure of the aquifer and the distribution of the Radium in the rock matrix.

In many cases, the concentration of Rn in water are "unsupported", meaning that there is relatively little Radium dissolved in the water giving rise to the $\mathrm{Rn}$ that is rather transferred into the water directly from the radioactive decay of the Radium in the solid materials in the aquifer.

Through research results people can have main formulas to measure $\mathrm{Rn}$ both in underground water and in drinking and sanitary water, Rn concentration that can cause health risks and some control technics too to reduce the risk for human health.

\section{Radon in the water}

With reference to $\mathrm{Rn}$ in underground water, the main data estimating the natural concentration in presence of radioactive rocks has been done by formula (1) [6] which gave the distribution of the $\mathrm{Rn}$ released at water rock interface into the water flowing as following: 
$\mathrm{Rn}=\frac{r A R a}{f\left[1-\exp \left(\frac{x}{v}\right)\right]} \exp \left(\frac{x^{\prime}}{v^{\prime}}\right)$

Where:

$\mathrm{r}=$ density of rock;

$A=$ ratio of $R n$ released into water to $R n$ generated in the rock

$\mathrm{Ra}=$ activity both of uranium and Radium contents of the rock

$\mathrm{f}=$ fractional pore space of the rock

$\mathrm{x}=$ distance covered with the aquifer;

$v=$ transport velocity of water after leaving the aquifer

If people knows hydrodynamic parameters of aquifer and both the pore size distribution and mineral composition of the rock formula (1) may estimate, sufficiently to our purposes, the concentration of Rn contents in common aquifer. Of course the increase of $\mathrm{Rn}$ concentration in water it is function of time too, as shown by following formula:

$\delta \mathrm{C}=\mathrm{Q} \delta \tau-\lambda \mathrm{C} \delta \tau$

where:

$\mathrm{C}=\mathrm{Rn}$ concentration

$Q=$ units of atom entering the water per unit of time

$\lambda=$ decay constant of $\mathrm{Rn}$

$\tau=$ time

If peoples integrates equation (2) for $\tau>>\lambda$, that is quite stationary liquid, the $\mathrm{Rn}$ concentration is given by the supply and decay rate.

It's developed [6] also following formula to estimate Rn concentration in natural fluid:

$$
\frac{C}{E}=\frac{1}{\varphi\left[1-\exp \left(\frac{\lambda \varphi \pi h}{Q\left(r w^{2} r c^{2}\right)}\right)\right]}
$$

where:

$\mathrm{C}=$ activity of $\mathrm{Rn}$ concentration

$E=R n$ flux emanating from the rock

$\lambda=$ decay constant of $\mathrm{Rn}$

$\varphi=$ porosity of the rock

$\mathrm{r}_{\mathrm{w}}=$ radius of cylindrical fracture in the rock of height $\mathrm{h}$

$r_{c}=$ radius of circular ring of rock which comprises the $r_{w}$ fracture from which Rn diffuses into the fracture

$\mathrm{Q}=$ flow rate.

As Rn gas is moderately soluble in water with which forms, by means of Van Der Waals forces, structures of $\mathrm{Rn} 6 \mathrm{H}_{2} \mathrm{O}$ type, that is clathrates [7], it is evident 
that the atom of $\mathrm{Rn}$ are polarised by the strong dipole of the water molecule. If ph values of water increase clathrates are destabilized with consequent transformation of $\mathrm{Rn}$ from liquid to gas phase [8].

Moreover, in the case of turbulent water flow with presence of gas bubbles in the aquifer, the transport of $\mathrm{Rn}$ atoms is due to their capacity to attach themselves to the bubbles of carrier gas [9].

If the energy amount of $\mathrm{Rn}$ in the interface Rn-bubble is minor than that of the isotope in water, $\mathrm{Rn}$ is carried by the bubbles at the velocity of same bubbles. People can see that coming from laminar water flow to high turbulent flow, that is the flow with very high numbers of bubbles per unit of volume of water, the $\mathrm{Rn}$ concentration can be changed by degassing of liquid phase. It is well know too that solubility of $\mathrm{Rn}$ in water depends on water temperature: the colder the water greater is the solubility of $\mathrm{Rn}$, as it is not so easy to characterise $\mathrm{Rn}$ solubized in each point of aquifer and than to calculate its concentration in water as there can be different both geological and flow-dynamical situations during the extent of the same aquifer.

The above showed formulas can give, to our purposes, only as very general role information about $\mathrm{Rn}$ concentration in the underground water and the same information can change during the course of year by changing of level of water creek. For all above said reasons it is in our opinion that the best way to know $\mathrm{Rn}$ concentration in water coming from subsoil it is to execute some experimental measurements, at least three or four times per year, really in the drawing points of sources of water supply as like as artesian wells, springs, lakes, water reservoirs and so on. Only after verifying during a significant time period, at least two o three years, that $\mathrm{Rn}$ in water has not health dangerous levels concentration than could be possible to reduce surveillance at one control measurement per year.

With reference, finally, to indoor use water, particularly in circumstances where the water is heated or aired such as in a shower or laundry, it happens releasing of $\mathrm{Rn}$ from water into the indoor air. The amount of $\mathrm{Rn}$ released per unit of $\mathrm{Rn}$ dissolved in the water depends upon water use rate for each kind of use and upon the efficiency is referred as transfer coefficient (tab. 1).

Table 1: Transfer Coefficient

Water use Transfer coefficient

\begin{tabular}{ll}
\hline Dish - washer & $0.95-0.90$ \\
Laundry & $0.92-0.88$ \\
Shower & $0.76-0.66$ \\
Bathtube & $0.42-0.38$ \\
WC & $0.34-0.22$ \\
\hline
\end{tabular}

Data on these parameters can be used to estimate the average contribution from water use to indoor airborne Rn concentration [10] by formula (4): 
$\frac{S w}{v}=\mathrm{C}_{\mathrm{w}} \sum_{i} \frac{W_{i} e_{i}}{V}$

where:

$\mathrm{S}_{\mathrm{w}}=$ activity per time unit of indoor $\mathrm{Rn}$ concentration coming from water;

$\mathrm{V}=$ volume

$\mathrm{C}_{\mathrm{w}}=$ activity per time unit of $\mathrm{Rn}$ concentration in water

$e_{i}=$ transfer coefficient function of kind use.

Dividing each side of formula (4) by the ventilation rate $\left(\lambda_{v}\right)$, yields the steady state air concentration $(\mathrm{Ca})$.

The overall ratio of air to water $\mathrm{Rn}$ concentration can be estimated by formula (5):

$\mathrm{f}=\frac{C a}{C w}=\frac{S w}{V \lambda_{v}}=\frac{W * e}{V \lambda_{v}}$

where:

$\mathrm{W}=$ total per capita water use rate

$\mathrm{e}=$ use weighted transfer coefficient.

On average, almost complete transfer of $\mathrm{Rn}$ from water to air occurs when both heath and aeration or agitation are involved such as in a dish-washer or laundry.

\section{Radon measurements}

$\mathrm{Rn}$ is moderately soluble in water and its solubility depends on water temperature: the colder the water greater is the $\mathrm{Rn}$ solubility. To measure solubility in water is used the solubility coefficient defined as the ratio of $\mathrm{Rn}$ concentration in water to that in air.

As at $20^{\circ} \mathrm{C}$ the solubility coefficient is about 0.25 , it means that $\mathrm{Rn}$ is distributed preferentially in air rather than in water in the ratio $4: 1$.

By this ownership $\mathrm{Rn}$ in water can be easily measured after its extraction by bubbling air through the water or by extracting $\mathrm{Rn}$ from the water by organic liquid scintillators [11]

These kinds of measures can be referred only to a small sample of water, such as a very little reservoir, and to a particular time of sampling. But in the case of aquifer or artesian wells, or water creeks, the $\mathrm{Rn}$ distribution into the water may be not constant throughout the entire volume because there are many possibilities of big variations of $\mathrm{Rn}$ concentration in the water both during the time and in different positions in function of the parameters showed previously.

It is studied the absorption of radiogenic gasses in different polymers and since polyethylene is characterised by a certain solubility coefficient it may absorb Rn which can be measured at the end of exposure by $\gamma$ - spectrometry.

This techniques offers advantages to have possibility both to integrate $\mathrm{Rn}$ concentration over time and water volume and to measure $\mathrm{Rn}$ at any places of 
water volume, as like as in aquifers or big reservoir, by inserting in checked zones polyethylene foils direct in water.

However, there are many techniques to measure Rn concentration in water as such the analysis of the Rn daughters in equilibrium with the water and $\gamma$ counting detector used to measure the $\mathrm{Rn}$ concentration of water samples coming from detected source and collected in polyethylene or lucite modified Marinelli beakers [13].

For all above techniques it is necessary to have a very good care in handling and in carrying samples to prevent outgassing of Rn during both the process of collection and transport or storage.

A method more simple and not expensive is that one to use in situ passive detector as Alpha track detectors.

The device is an $\alpha$-track monitor inside a plastic container placed inside the water [13].

To relate the air Rn concentration in the container and that one in the water is used an empirically derived constant and manufacturers of devices assure that accuracy of measurements is better than $\pm 10 \%$ of error.

\section{Health risk concentration}

Radon in drinking or sanitary water presents main two kind of health risks: that one caused by inhalation of $\mathrm{Rn}$ holder into the water and the other one caused by ingestion of polluted water: the inhalation causes lung cancer and ingestion causes stomach cancer.

With reference to inhaled $\mathrm{Rn}$, that is $\mathrm{Rn}$ coming from the water into indoor air, there is not one fixing and official value of concentration because health limit has fixed in different ways by different Organisations: U.S. Environmental Protection Agency (EPA) gave the limit of $150 \mathrm{~Bq} / \mathrm{m}^{3}, \mathrm{CEE}$ - Euratom gave the limits of $200 \mathrm{~Bq} / \mathrm{m}^{3}$ in new buildings and $400 \mathrm{~Bq} / \mathrm{m}^{3}$ in old existing building, International Commission of Radiological Protection (ICPR) gives one limit range between 200 and $600 \mathrm{~Bq} / \mathrm{m}^{3}$.

Italy has no regulation on exposure to $\mathrm{Rn}$ in air concentration.

On the ground of results coming from National Radon Survey [14], which showed that about $1 \%$ of Italian dwellings have an annual average Rn concentration above $400 \mathrm{~Bq} / \mathrm{m}^{3}$ and about $5 \%$ higher than $200 \mathrm{~Bq} / \mathrm{m}^{3}$, two hypothesis were outlined by two Italian research groups [15] coming from Environmental Protection Agency and the National Institute of Health respectly. The first of one hypothesis was to adopt $400 \mathrm{~Bq} / \mathrm{m}^{3}$ single reference level, while the other one was a first step to be taken at the National Level Authority by permitting a range of values between 200 and $400 \mathrm{~Bq} / \mathrm{m}^{3}$ and the final decision of value, within the previously range, attributed to decision of Regional Authority in function of the importance of the Rn problem, the social and economic costs of choiced limit and health priorities.

About this matter in 1996 has started, under the sponsorship of Directorate General for Science, an European Research into Radon in Construction 
Concerted Action (ERRICCA) with the gol to develop a draft for an European regulation to be presented to European Commission.

With reference to limit concentration in indoor air, even if there are not yet official ERRICCA suggestions, it seems that safety limit could oscillate between 150 and $250 \mathrm{~Bq} / \mathrm{m}^{3}$.

However, based on estimates of the distribution for each of the four parameters in formula (5), the distribution for the overall transfer factor " $\mathrm{f}$ " can be estimated to have a geometric standard deviation of 2.88 and an average of $1.4 * 10^{-4}[10]$.

The results indicate that, on average a $\mathrm{Rn}$ concentration of $10.000 \mathrm{~Bq} / \mathrm{m}^{3}$ is needed to in order to yield an indoor air concentration of $1.0 \mathrm{~Bq} / \mathrm{m}^{3}$ due to use indoor of polluted water [16]

On the ground of above information people can see that probability to have significant indoor air Rn concentration coming from use of polluted water is quite small as some dangerous effects may start only for Rn concentration in the water up to $100^{*} 10^{4} \mathrm{~Bq} / \mathrm{m}^{3}$

With reference to ingestion of polluted water, as Rn solubilized in the water is introduced entirely in the human body it is logical conclusion that all $\gamma$-radiations emitted by $\mathrm{Rn}$ will hit digestive apparatus therefore is in our opinion that 100 $\mathrm{Bq} / \mathrm{m}^{3}$ concentration may be adopted as health limit concentration. Of course this is only an indicative safety dose because the risk coming from ingestion of polluted water depends also by somatic condition of people, as for $100 \mathrm{~Bq} / \mathrm{m}^{3}$ of Rn concentration people have different levels of risk between grow-up persons and infant, between sound and sick people and so on.

\section{Remedial action and control techniques}

Omitting the well known remedies for indoor air $\mathrm{Rn}$ [17] and with reference only to ingestion of $\mathrm{Rn}$ polluted water, there are three main techniques to reduce $\mathrm{Rn}$ concentration as following:

- Increasing water temperature such as to decrease Rn solubility which is inverse function of temperature. This way is rather limited by heating costs that are direct function both of initial water temperature and of volume.

- Increasing in the water ph rate $(7 \div 10)$ such as to decrease strong dipole of water molecule which polarise the atoms of $\mathrm{Rn}$ in clathrates $\left(\mathrm{Rn}^{2} \mathrm{H}_{2} \mathrm{O}\right)$ that are destabilized by ph increasing with the consequent passage of $\mathrm{Rn}$ from liquid to gas phase outdoor of water. This way is limited by ph range necessary to have drinking water. To reduce final ph rate after this process people can mix the high ph rate water with no polluted low ph rate water

- Degasing polluted water by insufflation in many points of its volume with high pressure air such as to cause both very turbulence water flow and many air bubbles high velocity flow into the water. The transport of $\mathrm{Rn}$ atoms outdoor water is due to their capability to cling themselves to bubble of carrier gas. If the energy degree of $\mathrm{Rn}$ at the Rn-bubbles interfaces is less than that of the same $\mathrm{Rn}$ in the water, pollutant is inclined to be carried out 
by growing up bubbles at their velocity [18]. This tecnichs offers both bigger efficiency and lower costs than the previously ones.

When $\mathrm{Rn}$ concentration in water is quite elevated all three way may be used in sequence as shown in fig. 2

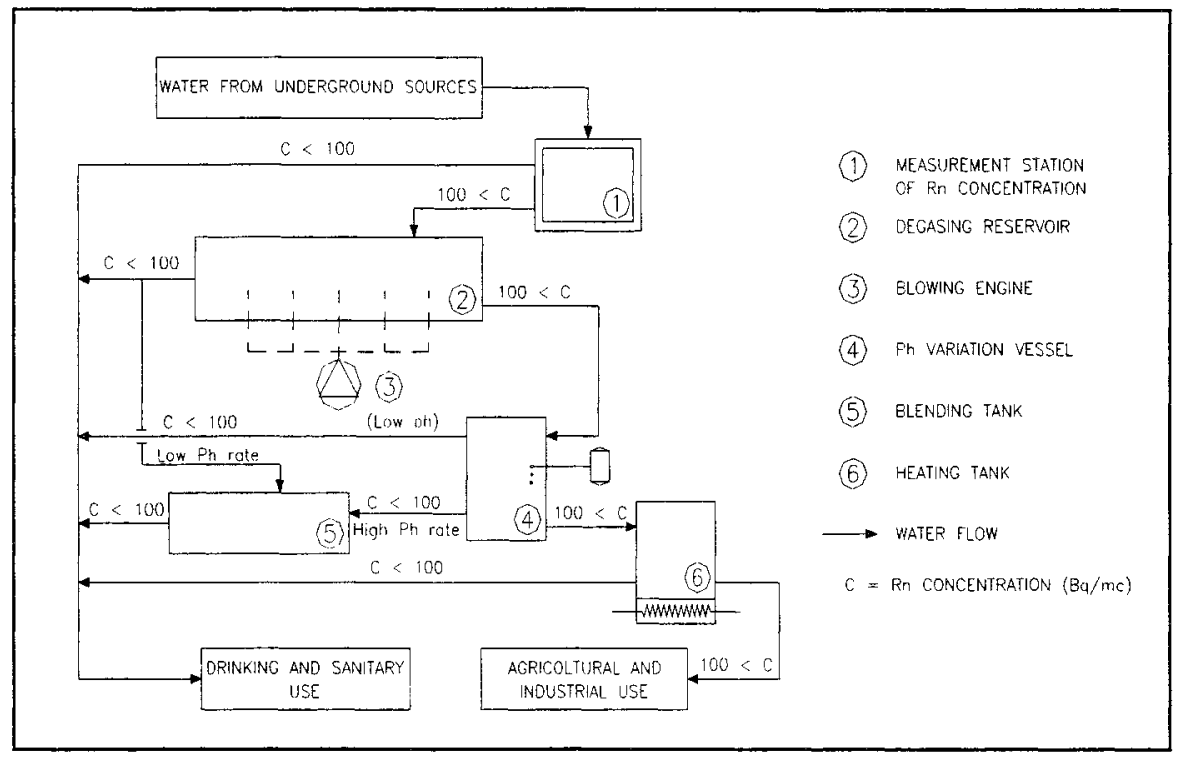

Figure 2: Control Actions to Reduce Rn concentration in water

\section{Conclusion}

For that said above, it is verified that there are many possibilities to have health dangerous $\mathrm{Rn}$ concentration in underground water and it is also proved that $\mathrm{Rn}$ in the water causes risks of cancer when people utilise such polluted water for drinking and sanitary use. The health hazard is worse since $\mathrm{Rn}$ presence in the water, like that in the air, is perceptible only after radioactive measurements. There are a lot of control tests provided for by law before people can utilise water for drinkable uses, but no tests refer to the radioactive hazard. Therefore, it is our opinion that this must be carried into effect by National or European Authorities the same actions of hazard assessment, that is:

- action to advertise that $\mathrm{Rn}$ in the water can represent big hazard for human health;

- action to fix, by results of researches, official maximum reference value of $\mathrm{Rn}$ concentration in drinkable or sanitary water;

- investigatory action on national sources of drinking water to control that level of $\mathrm{Rn}$ concentration is minor than that fixed for health safety;

- actions of subdivision of $\mathrm{Rn}$ concentration exceeding safety reference limit in some intervals, for example from 100 to $200 \mathrm{~Bq} / \mathrm{m}^{3}$, from 200 to 300 
$\mathrm{Bq} / \mathrm{m}^{3}$ and up $300 \mathrm{~Bq} / \mathrm{m}^{3}$, with the aim to assign the priority of public remedial intervention, in function of interval value.

\section{References}

[1]- National Council on Protection and Measurements (1987). Ionising Radiation Exposure of the Population of the United Stated, NCRP Report 93, Bethesda MD.

[2] Patania F., Gagliano A., (1994). Radon Secret and Detrimental Effect on Indoor Health, Proc. of 2 th International Conference Cold Climate HVAC, March 1994, Rowaniemy, Finland.

[3] U.S: Environmental Protection Agency (1992). A Citizen's Guide to Radon, EPA 402 - K92 -001, Washington, DC.

[4] Patania, F. (1995). Origini Patologie e Controllo dell'inquinamento da Radon. In: Condizionamento dell'Aria e Refrigerazione, vol. 12, pp. 1161-1168 and vol.13, pp.1247-1255.

[5] Laurence, E.P., Wanty, R.B:, and Nyberg, P. (1992). In: Contribution of ${ }^{222} \mathrm{Rn}$ in Domestic water Supplies to ${ }^{222} \mathrm{Rn}$ in Indoor Air in Colorado Homes, Health Physics, vol.62, pp 171-177.

[6] Stoker, A. And Kruger, P. (1975). Radon in Geothermal Reservoirs, Proc. Of 2th UN Symposium on Development and Use of Geothermal Resources, San Francisco (USA).

[7] Nesmeyanov, An.N. (1974). Radiochemistry, Mir Publisher, Moscow.

[8] Gasparini, P. And Veltri, C. (1987). Radon: un Precursore dei Terremoti?, Aree Sismogenesiche e Rischio Sismico in Italia, Eds. Boschi, E. And Dragoni, M. Pp. 585-609.

[9] Kristiansson, K. And Malmqvist, L. (1982). Evidence for Non diffusive Transport of Radon in the Ground and a New Physical Model for the transport, Geophysics, vol. 47 pp.1444-1452.

[10] Nararof, W., Doyle, s.M:, Nero, A.V. and Sextro, R.G. (1987) .Potable water as source of Airborne ${ }^{222} \mathrm{Rn}$ in U.S. Dwellings: A Review and Assessment, Health Physics, vol. 52, pp.281-295.

[11] Countess, R.J. (1978). Measurements of Radon-222 in Water, Health Physics, vol.34, pp.390-396.

[12] Labed, V. (1991). "Etude de la Permeation du Radon à Travers les Membranes Plastiques. Application à une Method de Measure du Radon dal l'Eau el les Sols Saturés. France: Brest University. Ph.D. Dissertation. Report CEA-R-55-880 CEN Saclay.

[13] Prichard, H.M., and Gesell, T., (1997) Rapid Measurements of Radon-222 Concentration in water with a Commercial Liquid Scintillation Counter, Health Physics, Vol. 133 pp. 577-586.

[14] Bochicchio, F., Campos Venuti, G. , Nuccetelli, C., Piermattei, S., Risica, S., Tommasino, L. and Torri, G. (1995). Scenario of Radon Indoors in Italy and Regulation Policy, Proc. Healthy Buildings 95, Milano 10-14 September 1995. Ed. M. Maroni vol. 2, pp.653-663. 


\section{Environmental Health Risk}

[15] Bochicchio, F., Campos Venuti, G. , Nuccetelli, C., Piermattei, S., Risica, S., Tommasino, L. and Torri, G. (1995). Results of the Representative Italian National Survey on Radon Indoor, Healthy Physics, vol. 71 pp.741-748.

[16] Lawrence E.P., Want, R.B: and Nyberg, P. (1992). Contribution of ${ }^{222} \mathrm{Rn}$ in Indoor Air in Colorado Homes, Healthy Physics, vol. 62 pp.171-177.

[17] Scivyer, C. and Woolliscroft, M. (1998). Radiation Remediation and Protective Measures in UK Buildings: the Work of the Building Research Establishment Ltd, UK Nuclear Technology Publishing, Radiation Protection Dosimetry, vol. 78, pp.39-44.

[18] Grammakov, A.G: (1936).On the Influence of Some factors in the Spreading of Radioactive Emanation Under Natural Conditions, Zhur Geafiz, vol. 6 , pp.123-148 